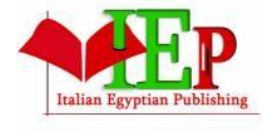

ISSN: $2735-5381$
INTERNATIONAL JOURNAL OF

FAMILY STUDIES, FOOD SCIENCE AND NUTRITION

HEALTH

VOLUME 4, ISSUE 2, 2021, 26-45.

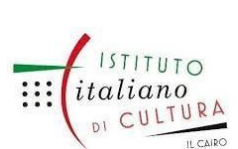

www.egyptfuture.org/ojs/

\title{
Extra Virgin Olive Oil as Nutritional Therapeutic Immuno-Enhancer
}

\author{
Rania I.M. Almoselhy
}

Oils and Fats Research Department, Food Technology Research Institute, ARC, Egypt

플 Correspondence: raniaalmoselhy@arc.sci.eg - (D) https://orcid.org/0000-0001-6314-6144

\begin{abstract}
Nutrition health is very important component in control of infectious diseases severity. Better nutrition is related to improved infant, child and maternal health, stronger immune systems, lower risk of non-communicable diseases (NCDs), and longevity. The current review shows the bioactive compounds, applications and potency of extra virgin olive oil (EVOO) as nutritional therapeutic immune-enhancer with evidence-based health benefits confirmed by scientific research works. The extensive literature survey revealed that EVOO is used for the treatment of stomach problems, diabetes, hypertension, diarrhea, respiratory and urinary tract infections, skin diseases, bacterial and fungal infections, hemorrhoids, rheumatism, asthma, and hair loss. Recent studies have been carried out focusing on evaluation of the antidiabetic, anticancer, antimicrobial, antifungal, antiviral, antioxidant, antihypertensive, gastroprotective, anti-inflammatory, antinociceptive, neuroprotective, and cardioprotective activities. EVOO as a valuable component of Mediterranean diet (MED), can help keep immune system strong and reduce the inflammation and oxidative stress that lead to a variety of diseases and conditions that increase risk for serious cases of COVID-19.
\end{abstract}

Keywords: Extra virgin olive oil, Nutritional therapeutics, Immuno-enhancer, COVID-19

\section{INTRODUCTION}

Global situation of 247,472,724 confirmed cases of COVID-19 including 5,012,337 deaths have been reported to WHO Coronavirus (COVID-19) Dashboard on $3^{\text {rd }}$ November 2021 [1]. Clinical presentation of COVID-19 varies from asymptomatic to severe pneumonia with acute respiratory distress syndrome (ARDS), with symptoms being fever, cough, and fatigue [2,3]. Comorbidities are strong risk factors for severe illness with most patients aged 30-79 years with at least one comorbidity as hypertension, diabetes, and cardiovascular disease (CVD) [3-5]. Approximately $14 \%$ of all COVID-19 cases are considered severe, about 5\% of all cases and $20 \%$ of the hospitalized population require admission to an intensive care unit (ICU) [6]. 
INTERNATIONAL JOURNAL OF

FAMILY STUDIES, FOOD SCIENCE AND NUTRITION

HEALTH

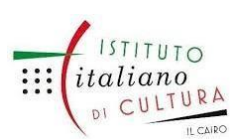

ISSN: $2735-5381$

VOLUME 4, ISSUE 2, 2021, 26-45.

www.egyptfuture.org/ojs/

Multiple chronic diseases or comorbidities, affect more than $70 \%$ of hospitalized patients associated with increased risk and prevalence of malnutrition. Therefore, prevention and treatment of malnutrition should be routinely included in management of COVID-19 patients (Figure 1). European Society for Clinical Nutrition and Metabolism (ESPEN) aims at providing concise guidance for nutritional management of COVID-19 patients [7-9].

\section{1: Check for Malnutrition}

Patients at risk for worst outcomes and higher mortality following infection with SARS-COV-2, namely older adults and polymorbid individuals, should be checked using the MUST criteria or, for hospitalized patients, the NRS-2002 criteria.

2: Optimization of the nutritional status Subjects with malnutrition should undergo diet counseling from an experienced professionals.

3: Supplementation with vitamins and minerals Subjects with malnutrition should ensure supplementation with vitamin $A$, vitamin $D$ and other micronutrients.

\section{4: Regular physical activity}

Patients in quarantine should continue regular physical activity while taking precautions.

\section{5: Oral nutrition supplements (ONS)}

ONS should be used whenever possible to meet patient's needs, when dietary counseling and food fortification are not sufficient to increase dietary intake and reach nutritional goals.

\section{6: Enteral nutrition (EN)}

In patients, whose nutritional requirements cannot be met orally, EN should be administered. Parenteral nutrition (PN) should be considered when EN is not indicated or unsufficient.

INDIVIDUALS AT RISK OR INFECTED WITH SARS-COV-2
7: Medical nutrition in non-intubated ICU patients If the energy target is not reached with an oral diet, ONS should be considered first and then EN treatment. If there are limitations for the enteral route it could be advised to prescribe peripheral PN in the population not reaching energyprotein target by oral or enteral nutrition.

8: Medical nutrition in intubated ICU patients I EN should be started through a nasogastric tube; post-pyloric feeding should be performed in patients with gastric intolerance after prokinetic treatment or in patients at highrisk for aspiration.

9: Medical nutrition in intubated ICU patients II In ICU patients who do not tolerate If full dose EN during the first week in the ICU ist not tolerated, initiating parenteral nutrition (PN) should be weighed on a case-by-case basis.

10: Nutrition in ICU patients with dysphagia Texture-adapted food can be considered after extubation. If swallowing is proven unsafe, EN should be administered.

ICU PATIENTS INFECTED WITH SARS-COV-2

Figure 1. Nutritional management in individuals at risk for severe COVID-19, in subjects suffering from COVID-19, and in COVID-19 ICU Patients [7].

Infection and malnutrition have always been intricately linked. Malnutrition is the primary cause of immunodeficiency worldwide associated with increased viral infection disease severity, as in case of influenza 1918 pandemic [10,11]. Malnutrition is associated with poor clinical outcomes among hospitalized patients, with 38-78\% of patients in ICU being malnourished [12]. 


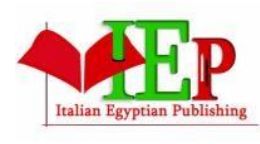

ISSN: 2735-5381
INTERNATIONAL JOURNAL OF

FAMILY STUDIES, FOOD SCIENCE AND NUTRITION

HEALTH

VOLUME 4, ISSUE 2, 2021, 26-45.

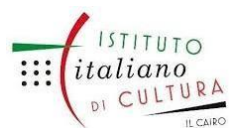

www.egyptfuture.org/ojs/

Despite the obviously important relationship between nutritional status and clinical outcomes in severely ill COVID-19 patients, the prevalence, severity, and treatment of malnutrition in this population remains to be fully elucidated [13]. The aim of the present work is to review the scientific evidence regarding the specific impact of EVOO consumption on human health as nutritional therapeutic immuno-enhancer with different diseases and during COVID-19.

\section{WHO DEPARTMENT OF NUTRITION FOR HEALTH AND DEVELOPMENT}

Nutrition is a critical part of health and development. Better nutrition is related to improved infant, child and maternal health, stronger immune systems, safer pregnancy and childbirth, lower risk of non-communicable diseases (such as diabetes and cardiovascular disease), and longevity. Healthy children learn better. People with adequate nutrition are more productive and can create opportunities to gradually break the cycles of poverty and hunger. Malnutrition, in every form, presents significant threats to human health. Today the world faces a double burden of malnutrition that includes both undernutrition and overweight, especially in low- and middle-income countries. WHO is providing scientific advice and decision-making tools that can help countries take action to address all forms of malnutrition to support health and wellbeing for all, at all ages. This fact file explores the risks posed by all forms of malnutrition, starting from the earliest stages of development, and the responses that the health system can give directly and through its influence on other sectors, particularly the food system [14].

\subsection{WHO NUTRITION AND FOOD SAFETY (NFS) AND COVID-19}

The Nutrition and Food Safety (NFS) Department in WHO is addressing the burden of disease from physical, chemical and microbial hazards in food and unhealthy diets, maternal and child malnutrition, overweight and obesity. It aims to ensure universal access to safe, sufficient nutritious food and effective nutrition actions, through setting science-based international food standards, promoting nutrition action in health systems, fostering sustainable food production and consumption, improving food environments and empowering consumers in all situations, monitoring nutrition status, and managing food safety events at the international level. A robust

food supply is an essential part of the health and nutrition response to COVID-19. WHO, together with partners, is providing nutrition and food safety guidance and advice during the COVID-19 pandemic for governments, food businesses, health workers and the general public, to maintain good health and prevent malnutrition in all its forms [15]. 


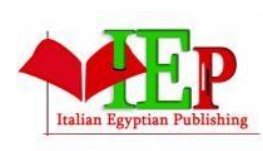

ISSN: 2735-5381
INTERNATIONAL JOURNAL OF

FAMILY STUDIES, FOOD SCIENCE AND NUTRITION

HEALTH

VOLUME 4, ISSUE 2, 2021, 26-45.

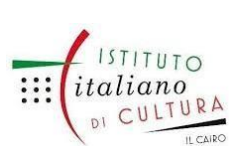

www.egyptfuture.org/ojs/

\subsection{WHO STANDARDS AND SCIENTIFIC ADVICE ON FOOD AND NUTRITION (SSA)}

The Standards and Scientific Advice on Food and Nutrition (SSA) Unit in WHO is the focal point for WHO's work on international standard-setting in food safety and nutrition. The Unit provides science-based food safety risk assessments and related evidence-based guidance on foodborne hazards, nutrient requirements across life stages as well as food safety and nutrition policy recommendations. SSA manages the Joint FAO/WHO Expert Committee on Food Additives (JECFA), Joint FAO/WHO Meeting on Pesticide Residues (JMPR), Joint FAO/WHO Expert Meetings on Microbiological Risk Assessment (JEMRA) and Joint FAO/WHO Expert Meeting on Nutrition (JEMNU) expert committees for WHO jointly with FAO. Through these committees, WHO develops scientific risk assessments to define safe exposure levels to various chemicals and microorganisms in our food as well as nutrition-related standards. Scientific advice from these WHO/FAO committees is the basis for the development of international food safety and quality standards by the Codex Alimentarius Commission, as well as national food safety standard-setting in many Member States. The Unit is also managing support for food safety capacity building in Member States through the Codex Trust Fund [16].

\subsection{WHO FOOD AND NUTRITION ACTIONS IN HEALTH SYSTEMS (AHS)}

The Food and Nutrition Actions in Health Systems (AHS) Unit in WHO assists countries with the application of essential nutrition actions delivered through healthcare and community platforms. AHS develops guidance on programs and policies, creates application tools, provides technical assistance, fosters global partnerships, and supports global advocacy to ensure that proven nutrition interventions are universally accessible to all relevant populations. The Unit addresses multiple forms of malnutrition, including wasting, stunting, obesity, and micronutrient deficiency and supports improvements in infant and young child feeding [17].

\section{NUTRITIONAL THERAPY}

"Nutritional Therapy", a system of healing based on the belief that food, in its whole and natural form, provides the substance needed to obtain and maintain a vibrant state of health. Nutritional Therapy uses food to prevent and reverse diseases that plague most western societies: diabetes, obesity, heart disease, arthritis, and depression. In order for food to be therapeutic, it must be nutrient-dense, measured in part by the nutrients and anti-nutrients, contained in consumed foods. Nutritional Therapy is also concerned with the way that foods are prepared and delivered for 


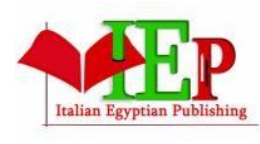

ISSN: 2735-5381
INTERNATIONAL JOURNAL OF

FAMILY STUDIES, FOOD SCIENCE AND NUTRITION

HEALTH

VOLUME 4, ISSUE 2, 2021, 26-45.

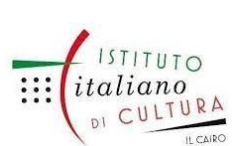

www.egyptfuture.org/ojs/

consumption. In order for foods to be therapeutically beneficial, the appropriate micro- and macronutrients must be delivered in a nutritionally dense format without contaminants. While plants are the main source of micronutrients, nutrient content can be altered with improper handling. Fruits and vegetables picked before their peak ripeness contain fewer phytochemicals. These phytochemicals protect plants them from all kinds of invaders, and when consumed, transfer these same protective advantages to the human body. Cooking and processing can further destroy vital properties of phytochemicals and antioxidants [18].

\subsection{NUTRIENTS}

Nutrients are plant and animal sources providing macronutrients (protein, carbohydrates, fat), micronutrients (vitamins, minerals, phytochemicals, antioxidants, probiotics), and fiber. They are whole and unprocessed vegetables, fruits, beans, legumes, whole grains, and raw nuts/seeds. Free range, grass-fed organic meat, dairy, eggs, and wild fish also qualify [18].

\subsection{ANTI-NUTRIENTS}

Anti-Nutrients are food products that have no biological necessity. Though edible, these are not considered "food": high fructose corn sweetener, sugars, artificial sweeteners, highly processed and hydrogenated fats, refined flour products, preservatives, and additives. Further, some critical nutrients become anti-nutrients when consumed in excess [18].

\subsection{INFLUENCE OF NUTRITIONAL FACTORS ON IMMUNOLOGICAL OUTCOMES}

Through food intake, humans obtain a variety of nutrients that are essential for growth, cellular function, tissue development, energy, and immune defense. A special interaction between nutrients and gut-associated lymphoid tissue occurs in the intestinal tract. Enterocytes of the intestinal barrier act as sensors for antigens from nutrients and the intestinal microbiota, which they deliver to the underlying immune system of the lamina propria, triggering an immune response. Studies investigating the mechanism of influence of nutrition on immunological outcomes have highlighted an important role of macronutrients (proteins, carbohydrates, fatty acids) and micronutrients (vitamins, minerals, phytochemicals, antioxidants, probiotics) in modulating immune homeostasis. Nutrients exert their role in innate immunity and inflammation by regulating the expression of TLRs, pro- and anti-inflammatory cytokines, thus interfering with immune cell crosstalk and signaling. Chemical substrates derived from nutrient metabolism may act as cofactors or blockers of enzymatic activity, influencing molecular pathways and chemical reactions 


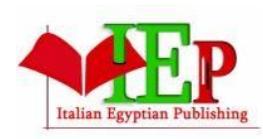

ISSN: $2735-5381$

INTERNATIONAL JOURNAL OF

FAMILY STUDIES, FOOD SCIENCE AND NUTRITION

HEALTH

VOLUME 4, ISSUE 2, 2021, 26-45.

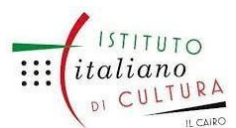

www.egyptfuture.org/ojs/

associated with microbial killing, inflammation, and oxidative stress. Immune cell function appears to be influenced by certain nutrients that form parts of the cell membrane structure and are involved in energy production and prevention of cytotoxicity. Nutrients also contribute to the initiation and regulation of adaptive immune responses by modulating $\mathrm{B}$ and $\mathrm{T}$ lymphocyte differentiation, proliferation and activation, and antibody production [19].

\section{PUBLIC HEALTH AND THE ROLE OF EXTRA VIRGIN OLIVE OIL}

The potential health benefits of olive oil consumption, particularly within Mediterranean diet (MED), was found to be beneficial for several chronic non-communicable diseases [20].

Figure 2 shows beneficial and healthy effects of the olive oil inclusion in MED [21-23].

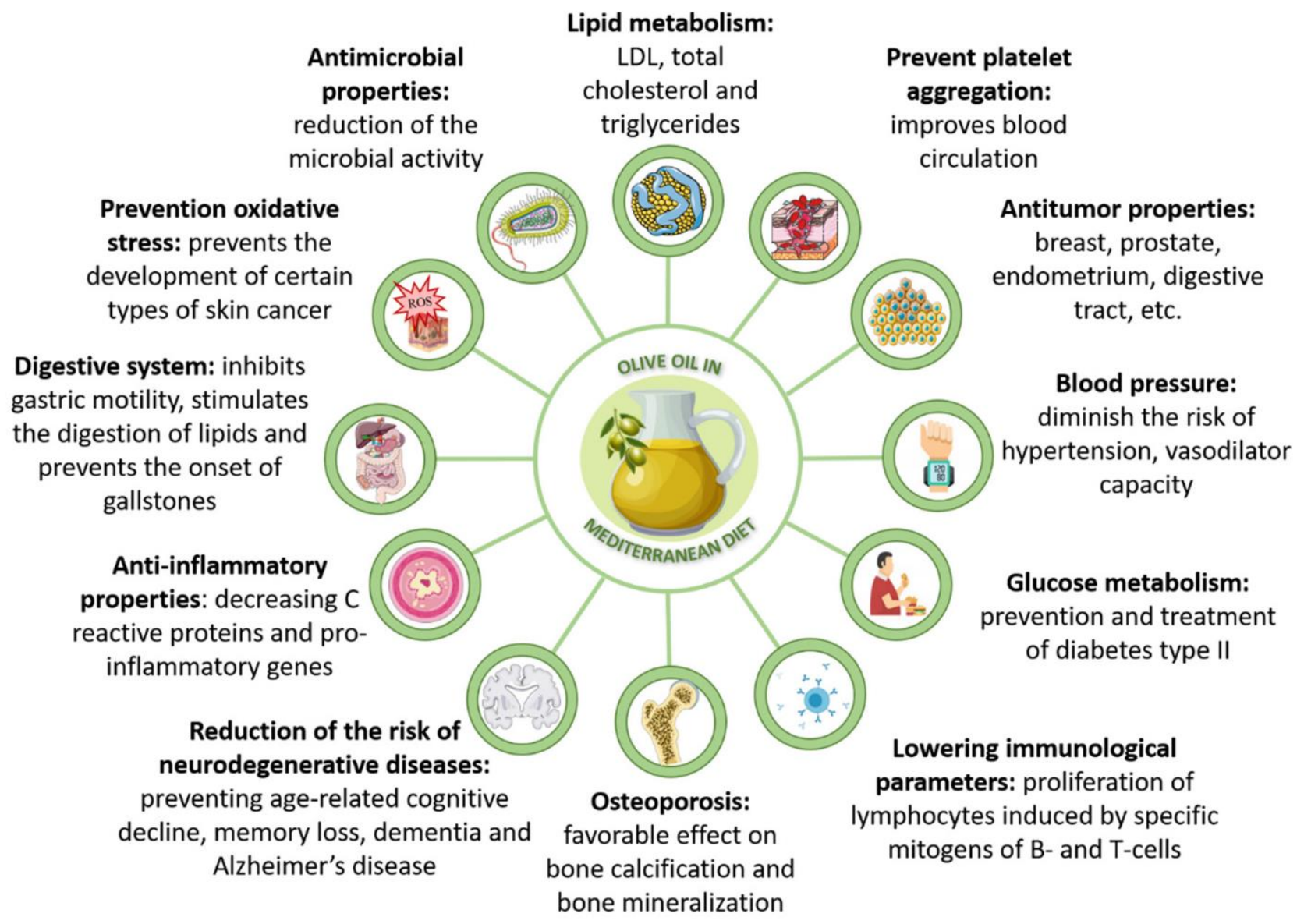

Figure 2. Beneficial and healthy effects of the olive oil inclusion in MED [21-23]. 
INTERNATIONAL JOURNAL OF

FAMILY STUDIES, FOOD SCIENCE AND NUTRITION

HEALTH

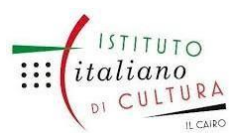

ISSN: $2735-5381$

VOLUME 4, ISSUE 2, 2021, 26-45.

www.egyptfuture.org/ojs/

\section{EXTRACTION OF EXTRA VIRGIN OLIVE OIL}

Figure 3 shows a summary of procedure of extraction and characterization (Generalities, Chemical composition, Bioactivities, Quality preservation) of extra virgin olive oil from olive fruits (Olea europaea L. of different varieties), whose extracting process follows a common line formed by different steps: collection, grading, washing, crushing, malaxing, separation and centrifugation, storage and packaging [21, 24, 25].

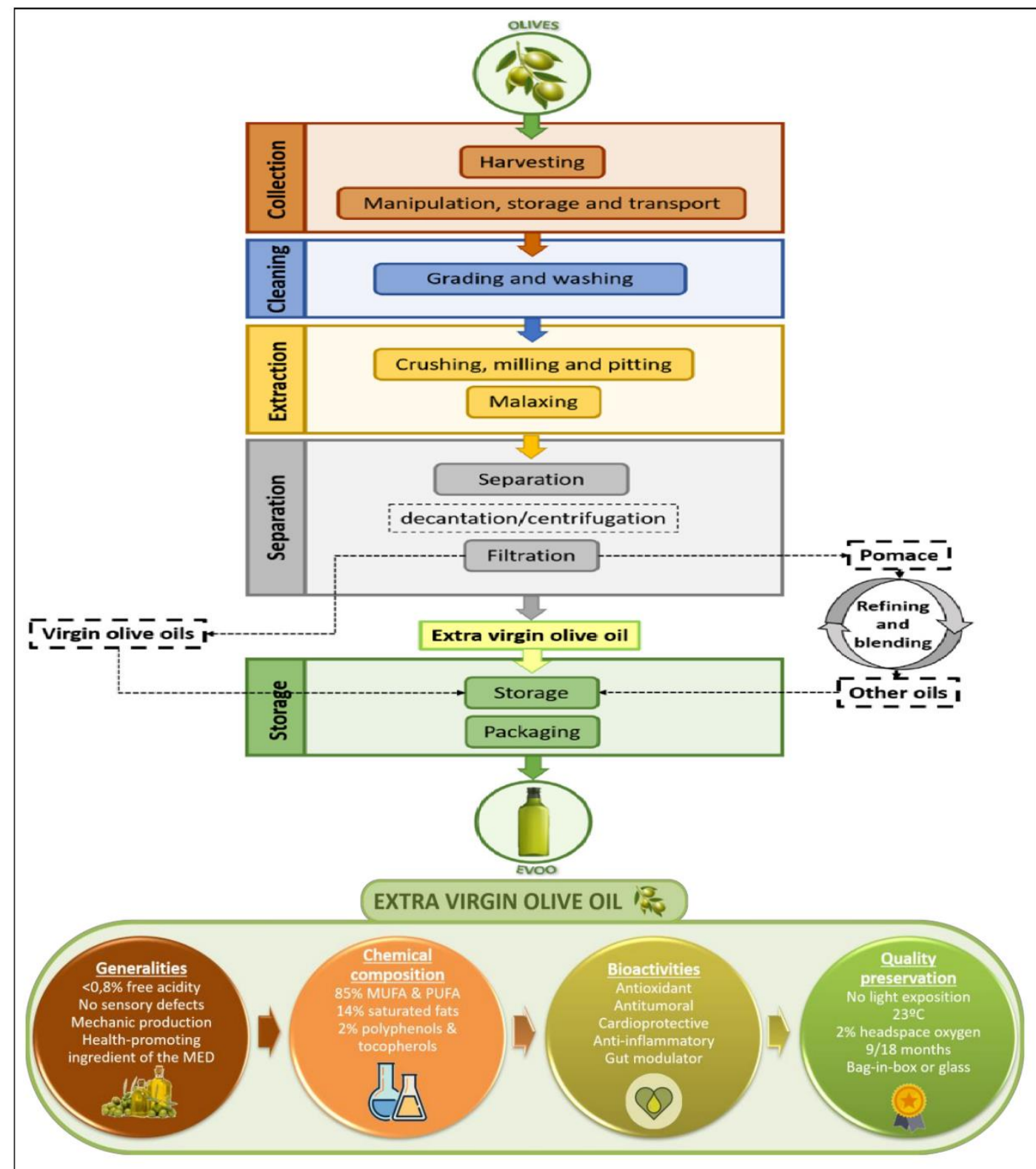

Figure 3. Summary of extraction and characterization of EVOO [21, 24, 25]. 
INTERNATIONAL JOURNAL OF

FAMILY STUDIES, FOOD SCIENCE AND NUTRITION

HEALTH

ISSN: $2735-5381$

VOLUME 4, ISSUE 2, 2021, $26-45$.

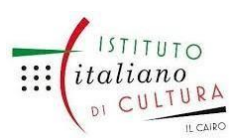

www.egyptfuture.org/ojs/

\section{QUALITY PARAMETERS OF EXTRA VIRGIN OLIVE OIL}

Olive oil qualification as "extra virgin" demands various requisites. On one hand, it must be obtained using exclusively mechanical procedures, which grants the "virgin" label. On the other hand, it must show a low free acidity $(<0.8 \%)$, low peroxide value, high antioxidant activity, a perceptible fruity taste and no sensory defects, acquiring in this way the label "extra". However, once those badges are achieved, it is important to attend to some storage factors to maintain and assure these quality characteristics until the oil is used [21, 26, 27]. Figure 4 shows a summary concerning the quality-involved parameters [21].

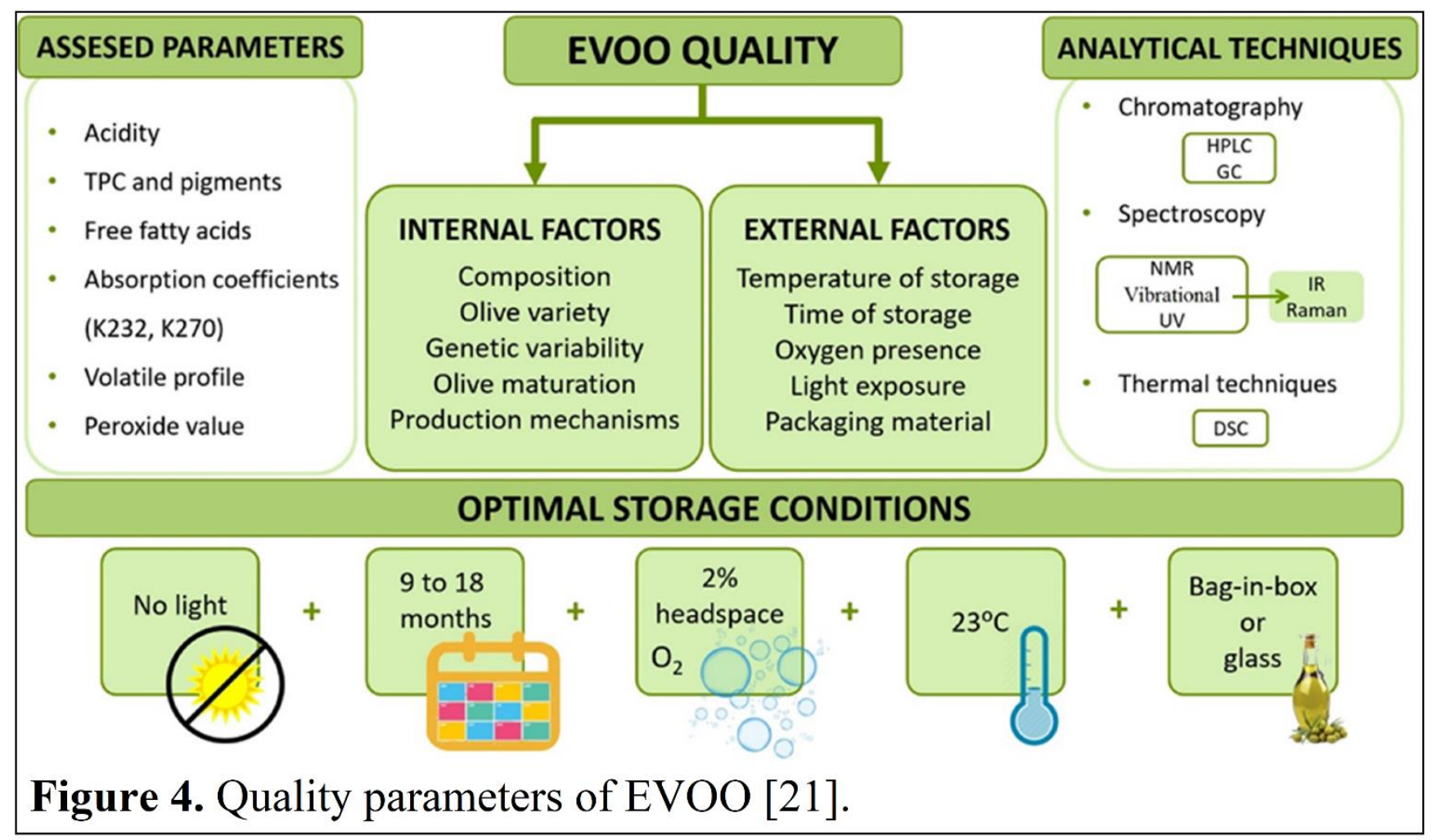

EVOO is extracted only by mechanical procedures using cold pressing. As the processing of EVOO does not require the use of high temperatures, 3-monochloropropanediol (3-MCPD) was not expected at quantifiable levels in EVOO. Knowing that 3-MCPD is heat-induced contaminant formed during the refining of vegetable oils under high temperatures, mainly during the deodorization step, then its occurrence in EVOO may be used as a good tool for authenticity, identity and quality parameter of EVOO with many methods such as UV-visible, FTIR spectroscopy, ${ }^{1} \mathrm{HNMR}, \mathrm{DSC}[28-30]$. 


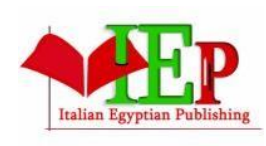

ISSN: 2735-5381
INTERNATIONAL JOURNAL OF

FAMILY STUDIES, FOOD SCIENCE AND NUTRITION

HEALTH

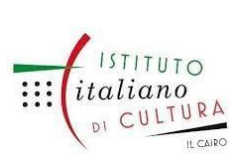

www.egyptfuture.org/ojs/

\section{COMPOSITION OF OLIVE OIL}

The major components of olive oil (OO) are saponifiable lipids ( 98\%), which are mostly triglycerols, MUFA (oleic acid, 55\%-83\%), PUFA (linoleic acid, 2.5\%-21\%) and SFA (palmitic acid, 7.5\%-20\%). The minor (unsaponificable) fraction ( 2\%) has more than 200 chemical compounds among which more than 30 are phenolic compounds, such as hydroxytyrosol, oleuropein, oleocanthal and tyrosol, phenolic acids (vanillic acid, syringic acid, gallic acid, etc), flavonoids (eriodictyol, apigenin, luteolin, etc.), secoiridoids (oleacein, oleocanthal, etc.) and lignans [31-41]. Figure 5. shows the main components of EVOO [38].

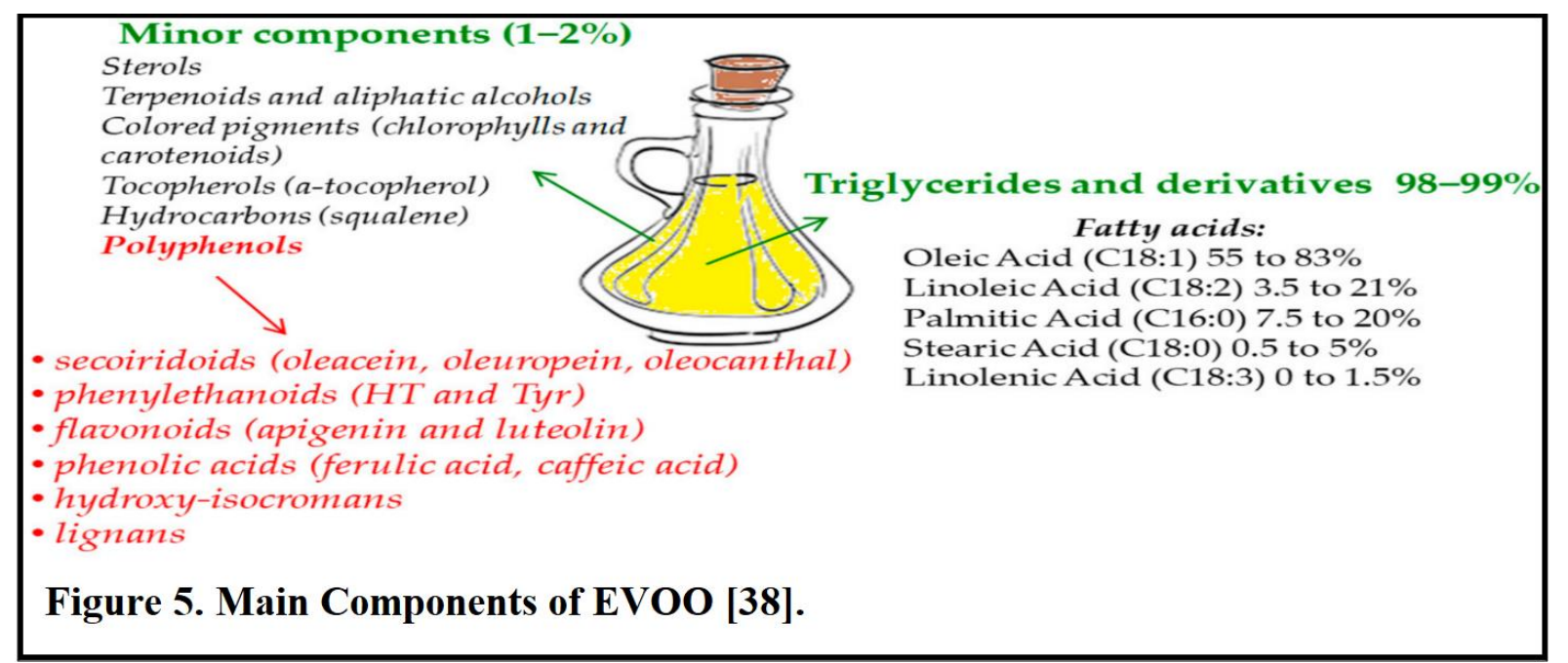

Olive oil lipid fraction (MUFA, PUFA) gives its lipophilic character responsible for protective properties on coronary, autoimmune and inflammatory disorders, granting antithrombotic and regulation effects of blood pressure [42]. The minor components like $\alpha$-tocopherol, tocotrienols, and carotenoids, such as $\beta$-carotene and lutein, squalene and other triterpenes, sterols, and pigments are also important for human health and they are responsible for the oil taste and aroma of olive oil. The chlorophyll (a non-oily component) in OO, determines the color of the OO that can be lost in the refining process. Its role is a facilitator of cell growth, and its part in the stimulation of the formation of blood cells (hematopoiesis) has been reported [43]. The bioactivity of the phenolic compounds is related to different properties, antioxidant and anti-inflammatory, although the molecular mechanism of these compounds in relation to many diseases could have different cellular targets [33]. Their content in OO varies depending on climate, cultivar, ripeness of the olives at harvesting, as well as the production process of the olive oil [38, 41, 44-50]. 


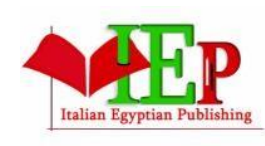

ISSN: 2735-5381
INTERNATIONAL JOURNAL OF

FAMILY STUDIES, FOOD SCIENCE AND NUTRITION

HEALTH

VOLUME 4, ISSUE 2, 2021, 26-45.

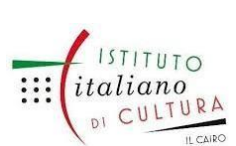

www.egyptfuture.org/ojs/

Different olive oil types are classified according to their acidity, expressed as amount of oleic acid (International Olive Council (IOC) standard). For instance, extra virgin olive oil (EVOO) has a free acidity of <0.8 grams / 100 grams, virgin olive oil (VOO) has a free acidity of <2 grams / 100 grams, and ordinary $\mathrm{OO}$ has a free acidity of $<3.3$ grams/100 grams. During the refining process some of the important components, like phenolic compounds and squalene, are lost; thus, EVOO is the olive oil with the highest phenolic compound content with the mean total polyphenol content of $>55 \mathrm{mg} / 100 \mathrm{~g}[41,44]$.

Among the many constituents of olive oil, particular attention has been focused to the phenolic compounds due to their antioxidant effects, but also to their anti-inflammatory activities since that inflammation is an important etiologic factor for several non-communicable diseases [33, 42, 45, 51]. There are various OO phenolic compounds, which can be classified as simple phenols (hydroxytyrosol, tyrosol), secoiridoids (oleuropein) and lignans. Among them, oleuropein, hydroxytyrosol and oleocanthal are the most studied compounds with proven benefits, such as being strong antioxidant compounds counteracting reactive oxygen species' formation [35, $37,41,52-55]$.

Although in a smaller quantity, other compounds such as tocopherols or polyphenols are also present, which are associated with the powerful antioxidant and inflammatory activity of EVOO, among other qualities. For all these reasons, the inclusion of this golden ingredient in the diet, in addition to offering characteristic organoleptic properties, provides substances capable of preventing the appearance or development of diseases of various nature, from heart and circulatory diseases to metabolic disorders, including carcinogenic processes. Compared to other types of olive oil, EVOO must meet more stringent requirements that give it the right to possess that nomenclature. However, it is a shame that, during distribution and storage, the previously achieved quality is corrupted, leaving some of its most distinguished and desirable properties on the way. Therefore, the factors that promote the degradation of its components must be known, intending to reduce the negative impact that may originate in EVOO and thus increasing its shelf-life. These factors can be divided into intrinsic factors, such as the variety of olives and their cultivation conditions, about which little can be done once EVOO has been produced; and external factors, which include exposure to light, temperature, time or the type of material used for packaging [42]. 


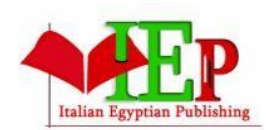

ISSN: $2735-5381$
INTERNATIONAL JOURNAL OF

FAMILY STUDIES, FOOD SCIENCE AND NUTRITION

HEALTH

VOLUME 4, ISSUE 2, 2021, 26-45.

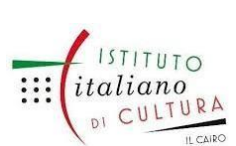

www.egyptfuture.org/ojs/

\section{IMMUNOLOGICAL IMPACTS OF EXTRA VIRGIN OLIVE OIL}

Immune cell plasticity is mainly involved in pathogenesis of chronic inflammatory autoimmune processes. Dietary fatty acids and (poly) phenols, modulate the immune response for prevention and management of illnesses [56]. PUFA contribute to the suppression of immune system functions with beneficial effects on human health. EVOO is capable of modulating several immune functions, but it does not reduce host immune resistance to infectious microorganisms. Based on these criteria, EVOO may exert beneficial effects on the human health and especially on immune system, because it contributes to the reduction of typical inflammatory activity observed in patients suffering from autoimmune disorders, but without exacerbating the susceptibility to pathogen agents [57]. Effects of EVOO have usually been ascribed to its apolar lipids or to oleic acid with (poly) phenols possess anti-inflammatory and immune-regulatory effects. This notion triggered research on EVOO and its bioactive components as an alternative nutritional therapeutic strategy for immune-inflammatory diseases such as inflammatory bowel disease (IBD), rheumatoid arthritis (RA), systemic lupus erythematosus (SLE) and sclerosis, shown in Figure 6 [58].
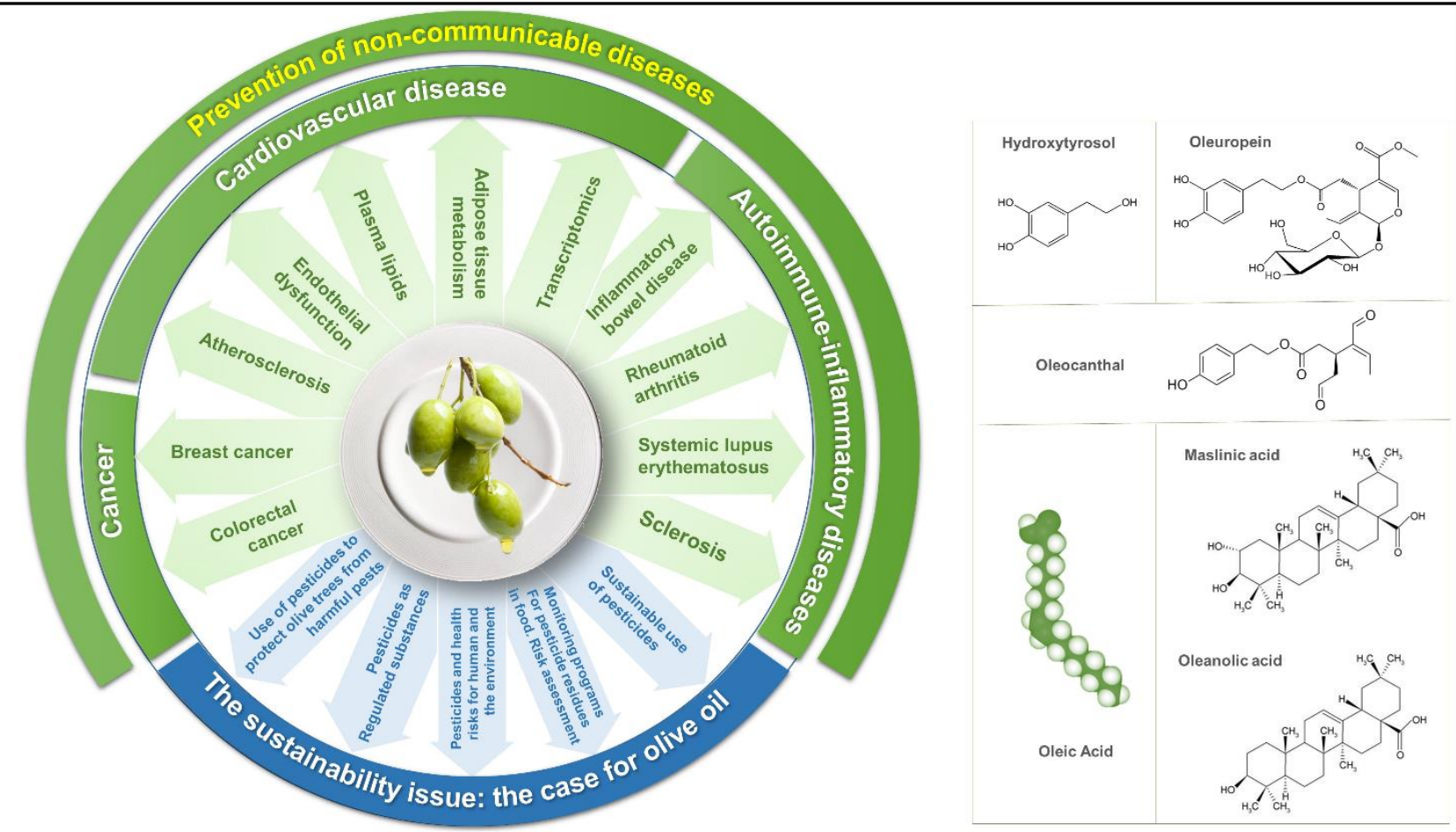

Figure 6. Role of EVOO in prevention of non-communicable diseases [58]. 


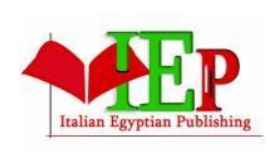

ISSN: 2735-5381

\section{INTERNATIONAL JOURNAL OF \\ FAMILY STUDIES, FOOD SCIENCE AND NUTRITION \\ HEALTH}

VOLUME 4, ISSUE 2, 2021, 26-45.

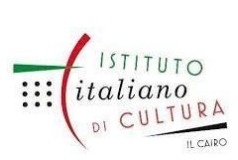

www.egyptfuture.org/ojs/

\section{EXTRA VIRGIN OLIVE OIL AND HEALTH: MOLECULAR MECHANISMS}

It is likely that if olive (poly) phenols have chemopreventive properties, these are due to a variety of molecular actions rather than to a single one. One example is that of oleocanthal (OC), which was shown as cytotoxic to human melanoma cells, but not to normal dermal fibroblasts; its molecular actions include the inhibition of ERK1/2 and AKT phosphorylation and downregulation of Bcl-2 expression. OC inhibits cell growth more effectively than classic pharmaceutical COX inhibitors; in addition, OC inhibits colony formation and induces apoptosis-by PARP cleavage, activation of caspases 3/7, and chromatin condensation - in hepatocellular carcinoma (HCC) and colorectal cancer (CRC) cells. OC has the potential to inhibit the growth of hormone-dependent breast cancer and improve sensitivity to tamoxifen therapy [58].

Oleuropein (OL) also inhibits HepG2 (human hepatoma) viability via the induction of apoptosis (i.e., upregulation of BAX and downregulation of $\mathrm{Bcl}-2$ ), activation of the caspase pathway, and modulation of the phosphatidylinositol 3 kinase/protein kinase B (PI3K/AKT) signaling pathway, in turn suppressing the expression of activated AKT. A combination of OLE and cisplatin shows synergistic effects, i.e., as compared with the addition of individual molecules effects in HepG2, leading to an increase of NO and of the pro-nerve growth factor (NGF)/NGF ratio. This is accompanied by a dose-dependent upregulation of caspase- 3 and a concomitant downregulation of MMP-7 gene expression [58].

With regards hydroxytyrosol (HT), some papers reported chemoprevention via prevention of DNA damage in PBMC and inhibition of breast (MDA and MCF-7), prostate (LNCap and PC3) and colon (SW480 and HCT116) cancer cell proliferation. HT reduces papillary (TPC-1, FB-2) and follicular (WRO) thyroid cancer cell proliferation and viability by promoting apoptotic cell death via intrinsic pathways. However, these experiments were performed with high doses of HT, which diminishes their physiological relevance. HT and two of its colonic metabolites (phenylacetic and hydroxyphenylpropionic acids) are able to arrest the cell cycle and promote apoptosis in HT-29 and Caco-2 cells. Oleacin, another phenolic compound found in EVOO, has been described to inhibit tumor-initiating cells by metabolic and epigenetic mechanisms using concentrations close to physiologic metabolism. Cellular senescence, which impairs the proliferation of damaged cells, also plays a role in aging and age-related diseases (including cancer) and is an interesting therapeutic target [58]. 


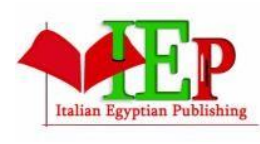

ISSN: 2735-5381
INTERNATIONAL JOURNAL OF

FAMILY STUDIES, FOOD SCIENCE AND NUTRITION

HEALTH

VOLUME 4, ISSUE 2, 2021, 26-45.

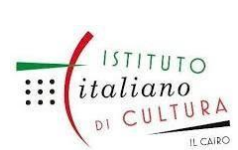

www.egyptfuture.org/ojs/

An imbalance of the redox code increased inflammation, and deregulation of cell cycle concur to alter cellular replication. Major players include the activation of some transcription factors, such as NF- $\mathrm{BB}$, signal transducer and activator of transcription 3 (STAT3), MAPK, and the hypoxia-inducible factor $1 \alpha$ (HIF $1 \alpha)$. These transcription factors dictate the production of inflammatory mediators, e.g., cytokines and chemokines and the activation of $\mathrm{COX} 2$, in turn recruiting and activating leukocytes and triggering the inflammasome of tumor cells, resulting in more inflammatory mediators being produced and a cancer-related inflammatory microenvironment being generated and propagated in a vicious cycle. Therefore, we can hypothesize that olive (poly)phenols would primarily act as anti-inflammatory molecules, but their manifold actions on cell signaling could also contribute to chemoprevention [58].

In summary, olive oil and its (poly) phenols might play important roles in lessening cancer risk, as observed in the Mediterranean area. Whether the association between olive oil consumption and chemoprevention is causal or casual is worth further investigation, but - even though human trials are impractical — the advice to consume olive oil as the predominant source of fat to lower cancer risk rests on solid bases [58].

\section{HEALTH BENEFITS OF EXTRA VIRGIN OLIVE OIL}

The extensive literature survey revealed Olea europaea (Olive Tree) to be a sacred and important medicinal plant used for the treatment of stomach problems, diabetes, hypertension, diarrhea, respiratory and urinary tract infections, skin diseases, bacterial and fungal infections, hemorrhoids, rheumatism, asthma, and hair loss. Pharmacological studies carried out on the fresh plant materials, crude extracts, and isolated components of Olea europaea provide a reasonable support for its various traditional uses. Recent studies have been carried out focusing on evaluation of the antidiabetic, anticancer, antimicrobial, antifungal, antiviral, antioxidant, antihypertensive, gastroprotective, anti-inflammatory, antinociceptive, neuroprotective, and cardioprotective activities. Most of the mentioned pharmacological studies were aimed at confirming its traditional uses. It has been found that some of its traditional uses like antioxidant, antidiabetic, anticancer, and so forth have extensively been explored by several researchers. Most of the pharmacological studies carried out on Olea europaea have been conducted on crude extracts of different parts of the plant and very few pharmacological reports are present for pure compounds isolated from the 


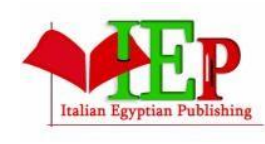

ISSN: $2735-5381$
INTERNATIONAL JOURNAL OF

FAMILY STUDIES, FOOD SCIENCE AND NUTRITION

HEALTH

VOLUME 4, ISSUE 2, 2021, 26-45.

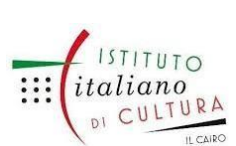

www.egyptfuture.org/ojs/

title plant of which oleuropein, maslinic acid, oleanolic acid, and so forth are the most abundant and notable. Thus it is somehow difficult to reproduce the results of all the studies and pinpoint the exact bioactive metabolites. Hence, there is a further need of studying the pure isolates for their pharmacological properties. Phytochemical research carried out on Olea europaea has led to the isolation of many classes of compounds like iridoids, secoiridoids, lignans, biophenols, flavonoids, flavone glycosides, isochromans, and terpenoids, from less polar fractions but the polar fractions, that is, $n$-butanol and water soluble fractions, still possess a vast scope for further phytochemical studies. The outcome of already reported phytochemical studies should further expand its therapeutic potential for further pharmacological studies, especially in vivo studies [59].

\section{CONCLUSIONS}

Extra virgin olive oil (EVOO) as a valuable component of MED human diets, has been used for medicinal purposes since ancient times. EVOO is considered as nutritional therapeutic immune-enhancer during COVID-19, as EVOO can help keep immune system strong and reduce the inflammation and oxidative stress that lead to a variety of diseases and conditions that increase risk for serious cases of COVID-19.

12. CONFLICT OF INTEREST: The author declares no conflict of interest.

\section{REFERENCES}

[1] WHO Coronavirus (COVID-19) Dashboard (Accessed on $3^{\text {rd }}$ November 2021). https://covid19.who.int

[2] Huang, C., Wang, Y., Li, X., Ren, L., Zhao, J., Hu, Y., et al. (2020). Clinical features of patients infected with 2019 novel coronavirus in Wuhan, China. Lancet, 395(10223),497-506. https://doi.org/10.1016/s0140-6736(20)30183-5

[3] Liu, H., Chen, S., Liu, M., Nie, H., Lu, H. (2020). Comorbid Chronic Diseases are Strongly Correlated with Disease Severity among COVID-19 Patients: A Systematic Review and MetaAnalysis. Aging Dis., 11(3),668-678. https://doi.org/10.14336/ad.2020.0502

[4] Richardson, S., Hirsch, J.S., Narasimhan, M., Crawford, J.M., McGinn, T., Davidson, K.W., et al. (2020). Presenting Characteristics, Comorbidities, and Outcomes Among 5700 Patients Hospitalized With COVID-19 in the New York City Area. JAMA, 323(20),2052-2059. https://doi.org/10.1001/jama.2020.6775 


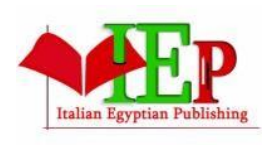

ISSN: $2735-5381$
INTERNATIONAL JOURNAL OF

FAMILY STUDIES, FOOD SCIENCE AND NUTRITION

HEALTH

VOLUME 4, ISSUE 2, 2021, 26-45.

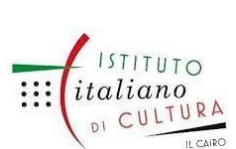

www.egyptfuture.org/ojs/

[5] Wu, C., Chen, X., Cai, Y., Xia, J., Zhou, X., Xu, S., et al. (2020). Risk Factors Associated With Acute Respiratory Distress Syndrome and Death in Patients With Coronavirus Disease 2019 Pneumonia in Wuhan, China. JAMA Intern Med., 180(7),934-943. https://doi.org/10.1001/jamainternmed.2020.0994

[6] Wiersinga, W.J., Rhodes, A., Cheng, A.C., Peacock, S.J., Prescott, H.C. (2020). Pathophysiology, Transmission, Diagnosis, and Treatment of Coronavirus Disease 2019 (COVID19): A Review. JAMA, 324(8),782-793. https://doi.org/10.1001/jama.2020.12839

[7] Barazzoni, R., Bischoff, S.C., Breda, J., Wickramasinghe, K., Krznaric, Z., Nitzan, D., Pirlich, M., Singer, P. (2020). ESPEN expert statements and practical guidance for nutritional management of individuals with SARS-CoV-2 infection. Clin Nutr., 39(6),1631-1638. https://doi.org/10.1016/j.clnu.2020.03.022

[8] Gomes, F., Schuetz, P., Bounoure, L., Austin, P., Ballesteros-Pomar, M., Cederholm, T., et al. (2018). ESPEN guidelines on nutritional support for polymorbid internal medicine patients. Clin Nutr., 37(1),336-353. https://doi.org/10.1016/j.clnu.2017.06.025

[9] Steiner, C.A., Friedman, B. (2013). Hospital utilization, costs, and mortality for adults with multiple chronic conditions, Nationwide Inpatient Sample, 2009. Prev Chronic Dis., 10,E62. https://doi.org/10.5888/pcd10.120292

[10] Katona, P., Katona-Apte, J. (2008). The interaction between nutrition and infection. Clin Infect Dis, 46(10),1582-1588. https://doi.org/10.1086/587658

[11] Short, K.R., Kedzierska, K., van de Sandt, C.E. (2018). Back to the Future: Lessons Learned From the 1918 Influenza Pandemic. Front Cell Infect Microbiol., 8:343. https://doi.org/10.3389/fcimb.2018.00343

[12] Lew, C.C.H., Yandell, R., Fraser, R.J.L., Chua, A.P., Chong, M.F.F., Miller, M. (2017). Association Between Malnutrition and Clinical Outcomes in the Intensive Care Unit: A Systematic $\begin{array}{lllll}\text { Review. JPEN } \quad J \quad \text { Parenter } & \text { Enteral } & \text { Nutr., } & \text { 444-758. }\end{array}$ https://doi.org/10.1177/0148607115625638

[13] Thomas, S., Alexander, C., Cassady, B.A. (2021) Nutrition risk prevalence and nutrition care recommendations for hospitalized and critically-ill patients with COVID-19. Clinical Nutrition ESPEN 44,38-49. https://doi.org/10.1016/j.clnesp.2021.06.002

[14] WHO Department of Nutrition for Health and Development (Accessed on $25^{\text {th }}$ October 2021). 


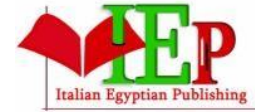

ISSN: $2735-5381$
INTERNATIONAL JOURNAL OF

FAMILY STUDIES, FOOD SCIENCE AND NUTRITION

HEALTH

VOLUME 4, ISSUE 2, 2021, 26-45.

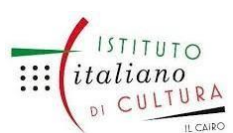

www.egyptfuture.org/ojs/

https://www.who.int/health-topics/nutrition

[15] WHO Nutrition and Food Safety (NFS) and COVID-19 (Accessed on 25 ${ }^{\text {th }}$ October 2021). https://www.who.int/teams/nutrition-and-food-safety/covid-19

[16] WHO Standards and Scientific Advice on Food and Nutrition (SSA) (Accessed on 25

October 2021). https://www.who.int/teams/nutrition-and-food-safety/standards-and-scientificadvice-on-food-and-nutrition

[17] WHO Food and Nutrition Actions in Health Systems (AHS) (Accessed on $25^{\text {th }}$ October 2021). https://www.who.int/teams/nutrition-and-food-safety/food-and-nutrition-actions-in-health-systems

[18] Koithan, M., Devika, J. (2010) New Approaches to Nutritional Therapy. J. Nurse Pract., 6 (10), 805-806. https://doi.org/10.1016/j.nurpra.2010.07.001

[19] Tourkochristou, E., Triantos, C., Mouzaki, A. (2021) The Influence of Nutritional Factors on $\begin{array}{llll}\text { Immunological } & \text { Outcomes. } & \text { Front } & \text { Immunol., }\end{array}$ https://doi.org/10.3389/fimmu.2021.665968

[20] Foscolou, A., Critselis, E., Panagiotakos, D. (2018). Olive oil consumption and human health: A narrative review. Maturitas, 118,60-66. https://doi.org/10.1016/j.maturitas.2018.10.013

[21] Jimenez-Lopez C., Carpena M., Lourenço-Lopes, C., Gallardo-Gomez, M., Lorenzo, J.M., Barba, F.J., Prieto, M.A., Simal-Gandara, J. (2020). Bioactive Compounds and Quality of Extra Virgin Olive Oil. Foods, 9(8),1014. https://doi.org/10.3390/foods9081014

[22] Pérez-Rodrigo, C., Aranceta, J. (2016). Olive Oil: Its Role in the Diet. In The Encyclopedia of Food and Health. ISBN 978-0-12-384953-3. Elsevier Ltd., 158-166. https://doi.org/10.1016/B978$\underline{0-12-384947-2.00502-X}$

[23] Yubero-Serrano, E.M., Lopez-Moreno, J., Gomez-Delgado, F., Lopez-Miranda, J. (2019). Extra virgin olive oil: More than a healthy fat. Eur. J. Clin. Nutr., 72, 8-17. https://doi.org/10.1038/s41430-018-0304-x

[24] Seçmeler, Ö., Galanakis, C.M. (2019). Olive Fruit and Olive Oil. In: Innovations in Traditional Foods. ISBN 978-0-12-814887-7. Woodhead Publishing, Sawston, UK, Chapter 8,193220. https://doi.org/10.1016/C2017-0-02480-1

[25] Peri, C. (2014). The Extra-Virgin Olive Oil Handbook. John Wiley \& Sons Ltd.: Hoboken, NJ, USA, ISBN 978-1-118-46045-0, John Wiley \& Sons, Ltd, Chapter 1,3-10. https://onlinelibrary.wiley.com/doi/book/10.1002/9781118460412 


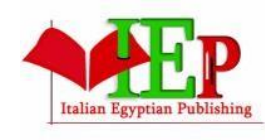

ISSN: 2735-5381
INTERNATIONAL JOURNAL OF

FAMILY STUDIES, FOOD SCIENCE AND NUTRITION

HEALTH

VOLUME 4, ISSUE 2, 2021, 26-45.

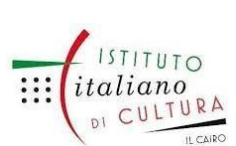

www.egyptfuture.org/ojs/

[26] Aroca-Santos, R., Lastra-Mejías, M., Cancilla, J.C., Torrecilla, J.S. (2018). Intelligent modelling to monitor the evolution of quality of extra virgin olive oil in simulated distribution conditions. Biosyst. Eng., 172, 49-56. https://doi.org/10.1016/j.biosystemseng.2018.05.007

[27] Calabria, D., Mirasoli, M., Guardigli, M., Simoni, P., Zangheri, M., Severi, P., et al. (2020). Paper-based smartphone chemosensor for reflectometric on-site total polyphenols quantification in olive oil. Sens. Actuators B Chem., 305, 127522. https://doi.org/10.1016/j.snb.2019.127522

[28] Kamikata, K., Vicente, E., Arisseto-Bragotto, A.P., Miguel, A.M.R.D.O., Milani, R.F., Tfouni, S.A.V. (2019). Occurrence of 3-MCPD, 2-MCPD and glycidyl esters in extra virgin olive oils, olive oils and oil blends and correlation with identity and quality parameters, Food Control, 95, 135-141, https://doi.org/10.1016/j.foodcont.2018.07.051

[29] Almoselhy, R.I.M., Eid, M.M., Abd El Baset, W.S., Aboelhassan, A.F.A. (2021) Determination of 3-MCPD in some Edible Oils using GC-MS/MS. Egyptian J Chem 64(3), 16391652. https://dx.doi.org/10.21608/ejchem.2021.64084.3373

[30] Almoselhy, R.I.M., Abd-Elmageed, S.M.M., Elsorady, M.E.I. (2019). Identification of Triacylglycerol Composition of Some Olive Oil Cultivars Cultivated in Some Different Areas in Egypt. Middle East Journal of Applied Sciences, 9(4), 963-968. https://dx.doi.org/10.36632/mejas/2019.9.4.13

[31] Boskou, D. (2008). Olive Oil: Minor Constituents and Health ( ${ }^{\text {st }}$ Edition) CRC Press. eBook ISBN 9780429136900, 1-248. https://doi.org/10.1201/9781420059946

[32] Mazzocchi, A., Leone, L., Agostoni, C., Pali-Schöll, I. (2019). The Secrets of the Mediterranean Diet. Does [Only] Olive Oil Matter? Nutrients, 11(12),2941. https://doi.org/10.3390/nu11122941

[33] Rodríguez-López, P., Lozano-Sanchez, J., Borrás-Linares, I., Emanuelli, T., Menéndez, J.A., Segura-Carretero, A. (2020). Structure-Biological Activity Relationships of Extra-Virgin Olive Oil Phenolic Compounds: Health Properties and Bioavailability. Antioxidants, 9(8),685. https://doi.org/10.3390/antiox9080685

[34] Mehmood, A., Usman, M., Patil, P., Zhao, L., Wang, C. (2020). A review on management of cardiovascular diseases by olive polyphenols. Food Sci Nutr., 8,4639-4655. https://doi.org/10.1002/fsn3.1668

[35] Lozano-Castellón, J., López-Yerena, A., Rinaldi de Alvarenga, J.F., del Castillo-Alba, J.R., 


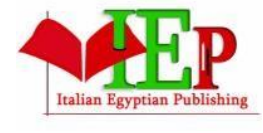

ISSN: $2735-5381$
INTERNATIONAL JOURNAL OF

FAMILY STUDIES, FOOD SCIENCE AND NUTRITION

HEALTH

VOLUME 4, ISSUE 2, 2021, 26-45.

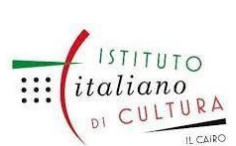

www.egyptfuture.org/ojs/

Vallverdú-Queralt, A., Escribano-Ferrer, E., Lamuela-Raventós, R.M. (2020). Health-promoting properties of oleocanthal and oleacein: Two secoiridoids from extra-virgin olive oil. Critical Reviews in Food Science and Nutrition, 60(15),2532-2548. https://doi.org/10.1080/10408398.2019.1650715

[36] Rocchetti, G., Senizza, B., Giuberti, G., Montesano, D., Trevisan, M., Lucini, L. (2020). Metabolomic Study to Evaluate the Transformations of Extra-Virgin Olive Oil's Antioxidant Phytochemicals During In Vitro Gastrointestinal Digestion. Antioxidants, 9(4), 302. https://doi.org/10.3390/antiox9040302

[37] Atlante, A., Amadoro, G., Bobba, A., Latina, V. (2020). Functional Foods: An Approach to Modulate Molecular Mechanisms of Alzheimer's Disease. Cells, 9(11), 2347. https://doi.org/10.3390/cells9112347

[38] Serreli, G., Deiana, M. (2020). Extra Virgin Olive Oil Polyphenols: Modulation of Cellular Pathways Related to Oxidant Species and Inflammation in Aging. Cells, 9(2), 478. https://doi.org/10.3390/cells9020478

[39] Gorzynik-Debicka, M., Przychodzen, P., Cappello, F., Kuban-Jankowska, A., Gammazza, A.M., Knap, N., et al. (2018). Potential Health Benefits of Olive Oil and Plant Polyphenols. Int. J. Mol. Sci., 19(3), 686. https://doi.org/10.3390/ijms19030686

[40] Romani, A, Ieri, F, Urciuoli, S, Noce, A, Marrone, G, Nediani, C, Bernini, R. (2019) Health Effects of Phenolic Compounds Found in Extra-Virgin Olive Oil, By-Products, and Leaf of Olea europaea L. Nutrients, 11(8), 1776. https://doi.org/10.3390/nu11081776

[41] Petkoska, A.T., Trajkovska-Broach, A. (2021). Health Benefits of Extra Virgin Olive Oil, Olive Oil - New Perspectives and Applications, Dr. Muhammad Akram, IntechOpen, DOI: 10.5772/intechopen.96570 Available from: https://www.intechopen.com/chapters/75509

[42] Jimenez-Lopez, C., Carpena, M., Lourenço-Lopes, C., Gallardo-Gomez, M., Lorenzo, J.M., Barba, F.J., Prieto, M.A., Simal-Gandara, J. (2020). Bioactive Compounds and Quality of Extra Virgin Olive Oil. Foods, 9(8), 1014. https://doi.org/10.3390/foods9081014

[43] Salazar, D.M., López-Cortés, I., Salazar-García, D.C. (2017). Olive Oil: Composition and Health Benefits. In: Olive Oil - Sensory Characteristics, Composition and Importance in Human Health. Nova Science Publishers Inc. ISBN: 978-1-53612-563-4, 1-38. https://novapublishers.com/shop/olive-oil-sensory-characteristics-composition-and-importance-in- 


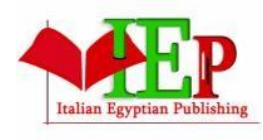

ISSN: 2735-5381
INTERNATIONAL JOURNAL OF

FAMILY STUDIES, FOOD SCIENCE AND NUTRITION

HEALTH

VOLUME 4, ISSUE 2, 2021, 26-45.

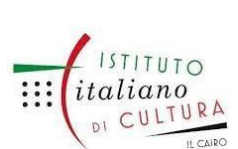

www.egyptfuture.org/ojs/

human-health

[44] Tejada S, Pinya S, del Mar Bibiloni M, Tur JA, Pons A, Sureda A. (2017). Cardioprotective Effects of the Polyphenol Hydroxytyrosol from Olive Oil. Current Drug Targets, 18(13), 14771486. https://doi.org/10.2174/1389450117666161005150650

[45] Presti, G., Guarrasi, V., Gulotta, E., Provenzano, F., Provenzano, A., Giuliano, S., et al. (2017). Bioactive compounds from extra virgin olive oils: Correlation between phenolic content and oxidative stress cell protection. Biophysical Chemistry, 230, 109116. https://doi.org/10.1016/j.bpc.2017.09.002

[46] Guasch-Ferré, M., Hu, F.B., Martínez-González, M.A. et al. (2014). Olive oil intake and risk of cardiovascular disease and mortality in the PREDIMED Study. BMC Med. 12(78). https://doi.org/10.1186/1741-7015-12-78

[47] Marcelino, G., Hiane, P.A., de Cássia Freitas, K., Santana, L.F., Pott, A., Donadon, J.R., de Cássia Avellaneda Guimarães, R. (2019). Effects of Olive Oil and Its Minor Components on Cardiovascular Diseases, Inflammation, and Gut Microbiota. Nutrients, 11(8),1826. https://doi.org/10.3390/nu11081826

[48] Lanza, B., Ninfali, P. (2020). Antioxidants in Extra Virgin Olive Oil and Table Olives: Connections between Agriculture and Processing for Health Choices. Antioxidants. 9(1), 41. https://doi.org/10.3390/antiox9010041

[49] Preedy, V.R., Watson, R.R. (2020). The Mediterranean Diet: An Evidence-Based Approach. Second Edition, ISBN 978-0-12-818649-7, Elsevier Inc. https://doi.org/10.1016/C2018-0-03968-7

[50] Hoffman, R., Gerber, M. (2015). Food Processing and the Mediterranean Diet. Nutrients, 7(9), 7925-7964. https://doi.org/10.3390/nu7095371

[51] Fernandes, J., Fialho, M., Santos, R., Peixoto-Placido, C., Madeira, T., Sousa-Santos, N., Virgolino, A., Santos, O., Vaz Carneiro, A. (2020). Is olive oil good for you? A systematic review and meta-analysis on anti-inflammatory benefits from regular dietary intake. Nutrition, 69, 110559. https://doi.org/10.1016/j.nut.2019.110559

[52] Francisco, V., Ruiz-Fernández, C., Lahera, V., Lago, F., Pino, J., Skaltsounis, L., et al. (2019). Natural Molecules for Healthy Lifestyles: Oleocanthal from Extra Virgin Olive Oil. J. Agric. Food Chem., 67(14, 3845-3853. https://doi.org/10.1021/acs.jafc.8b06723

[53] Klimova, B., Novotný, M., Kuca, K., Valis, M. (2019). Effect Of An Extra-Virgin Olive Oil 


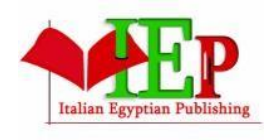

ISSN: $2735-5381$

\section{INTERNATIONAL JOURNAL OF \\ FAMILY STUDIES, FOOD SCIENCE AND NUTRITION \\ HEALTH}

VOLUME 4, ISSUE 2, 2021, 26-45.

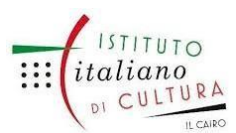

www.egyptfuture.org/ojs/

Intake On The Delay Of Cognitive Decline: Role Of Secoiridoid Oleuropein? Neuropsychiatr Dis Treat., 15, 3033-3340. https://doi.org/10.2147/ndt.s218238

[54] Hidalgo-Mora, J.J., Cortés-Sierra, L, García-Pérez, M.A., Tarín, J.J., Cano A. (2020). Diet to Reduce the Metabolic Syndrome Associated with Menopause. The Logic for Olive Oil. Nutrients, 12, 3184. https://doi.org/10.3390/nu12103184

[55] Perez-Jimenez, F., Ruano, J., Perez-Martinez, P., Lopez-Segura, F., Lopez-Miranda, J. (2007). The influence of olive oil on human health: not a question of fat alone. Mol. Nutr. Food Res., 51, 1199-1208. https://doi.org/10.1002/mnfr.200600273

[56] Ricordi, C., Garcia-Contreras, M., Farnetti, S. (2015). Diet and Inflammation: Possible Effects on Immunity, Chronic Diseases, and Life Span. J. Am. Coll. Nutr., 34, 10-13. https://doi.org/10.1080/07315724.2015.1080101

[57] Puertollano, M.A., Puertollano, E., Alvarez de Cienfuegos, G., de Pablo Martínez, M.A. (2010). Aceite de oliva, sistema inmune e infección [Olive oil, immune system and infection]. Nutr Hosp.,25(1),1-8. Spanish. https://pubmed.ncbi.nlm.nih.gov/20204249

[58] Gaforio, J.J., Visioli, F., Alarcón-de-la-Lastra, C., Castañer, O., et al. (2019). Virgin Olive Oil and Health: Summary of the III International Conference on Virgin Olive Oil and Health Consensus Report, JAEN (Spain) 2018. Nutrients, 11(9),2039. https://doi.org/10.3390/nu11092039 [59] Hashmi, M.A., Khan A., Hanif, M., Farooq, U., Perveen, S. (2015). Traditional Uses, Phytochemistry, and Pharmacology of Olea europaea (Olive). Evid Based Complement Alternat Med.,541591. https://doi.org/10.1155/2015/541591

Received: November 2021

Accepted: December 2021 